NBER WORKING PAPER SERIES

\title{
THE GENERATIONAL DIVIDE IN SUPPORT FOR ENVIRONMENTAL POLICIES: \\ EUROPEAN EVIDENCE
}

\author{
Joni Hersch \\ W. Kip Viscusi \\ Working Paper 11859 \\ http://www.nber.org/papers/w11859

\section{NATIONAL BUREAU OF ECONOMIC RESEARCH 1050 Massachusetts Avenue \\ Cambridge, MA 02138} \\ December 2005
}

Viscusi's research is supported by the Harvard Olin Center for Law, Economics, and Business and the Program on Empirical Legal Studies. We thank Christopher Lanese for research assistance. The views expressed herein are those of the author(s) and do not necessarily reflect the views of the National Bureau of Economic Research.

(C2005 by Joni Hersch and W. Kip Viscusi. All rights reserved. Short sections of text, not to exceed two paragraphs, may be quoted without explicit permission provided that full credit, including $\odot$ notice, is given to the source. 
The Generational Divide in Support for Environmental Policies: European Evidence

Joni Hersch and W. Kip Viscusi

NBER Working Paper No. 11859

December 2005

JEL No. Q25, H23

\begin{abstract}
This article examines age variations in support for environmental protection policies that affect climate change using a sample of over 14,000 respondents to a 1999 Eurobarometer survey. There is a steady decline with age in whether respondents are willing to incur higher gasoline prices to protect the environment. This relationship remains after controlling for socioeconomic characteristics. There are age-related differences in information about environmental risks, information sources about the environment, perceived health risks from climate change, and degree of worry about climate change. However, taking these factors into account does not eliminate the age variation in willingness to pay more for gasoline to protect the environment.

Joni Hersch

Harvard Law School

Cambridge, MA 02138

jhersch@law.harvard.edu

W. Kip Viscusi

Harvard Law School

Cambridge, MA 02138

and NBER

kip@law.ahrvard.edu
\end{abstract}




\section{Introduction}

Many environmental risks, including those posed by global warming, generate long-term hazards for society. The long-term nature of these risks requires that any effective policies must be sustained policy efforts for which the benefits will not be immediate. ${ }^{1}$ Our working hypothesis is that people's support for environmental policies is governed by their self interest. Maximizing one's own welfare may, of course, include concern for others alive now and possibly future generations as well. Indeed, U.S. interview evidence reported by Kempton (1991b) indicates that a desire to preserve the environment for one's descendents is often a prominent concern. However, because younger people have longer future remaining lifetimes, private welfare calculations will tend to include a larger direct personal benefit for the young than for the old. ${ }^{2}$

Decision making governed by self interest rather than broader social welfare calculations has potentially important ramifications for the age structure of support for environmental policies. This article examines support for gasoline price increases to protect the environment. Gasoline consumption is closely related to climate change. Because of the long-term character of climate change risks and the likely delay before there will be a payoff from policy initiatives, the degree to which different members of society will benefit directly from climate change policies will decline with age, with younger persons benefiting more from policies as they anticipate longer periods of exposure to problems associated with ongoing climate change. The possibility that there

\footnotetext{
${ }^{1}$ For a general discussion of alternative policies to address climate change problems, see Aldy, Barrett, and Stavins (2003), Schelling (1997), Barrett (2003), and Stewart and Weiner (2003).

${ }^{2}$ For similar reasons, studies such as that by Read and Read (2004) have shown that older individuals are more present-oriented with respect to financial rewards than are the young.
} 
will be intergenerational differences in support for climate change initiatives has been noted in the literature, but the empirical basis has not been explored in detail. ${ }^{3}$

The extent to which there will be intergenerational differences in support for higher gasoline prices will hinge on the source of these preferences. If the primary impetus for contributing to such policies is a bequest value with respect to future generations, then age-related differences may not be stark. One would expect greater age-related differences in preferences if there is a dominant role of individual use values, whereby the individuals themselves expect to benefit from policies that mitigate adverse environmental effects. Similarly, option values in which people thought that there was some probability that they would undertake activities that would be affected in a favorable way by environmental policies would also decline with age.

To examine these issues we use data from a 1999 Eurobarometer survey of European citizens. ${ }^{4}$ The focus on Europe makes possible an assessment of how information relating to climate change and support for environmental policies is reflected within countries that supported the Kyoto Protocol. Whereas the European Union ratified this international treaty that sought to reduce greenhouse gasoline emissions, the United States did not. European interview and survey data has, of course, been the focus of previous studies of the support for climate change policies and understanding of climate change risks, such as Löfstedt (1991) and Kempton and Craig (1993). What is unique about our study is that we examine risk beliefs regarding global warming and link these risk beliefs to a measure of willingness to pay to protect the environment.

\footnotetext{
${ }^{3}$ For a discussion of the intergenerational conflicts raised by climate change policies, see von Amsberg (1995).

${ }^{4}$ The 1999 survey is the most recent wave of the Eurobarometer survey that includes both global warming risk perception questions and willingness-to-pay to protect the environment questions.
} 
The Eurobarometer data provides a quite diverse sample, with respondents from 15 countries. After accounting for missing data, the sample consists of over 14,000 individual respondents. The Eurobarometer survey includes detailed information and precise questions pertaining to the individuals' willingness to pay higher gasoline prices if doing so would protect the environment. The gasoline price increase mechanism has a variety of attractive features in that it provides a concrete and meaningful payment mechanism for respondents. The data set also includes information on the extent of the respondents' environmental knowledge, their information sources, their perceived risks of global warming, and their support for policy initiatives, making it possible to explore age-related determinants of political support for policies to curb global warming.

Section 2 introduces evidence on the extent to which respondents are willing to support policies that boost gasoline prices. As the empirical results demonstrate, the willingness to incur higher gasoline prices is quite modest, perhaps in part because gasoline prices in Europe are already high. However, what is of greatest interest is that there are strong age-related variations in the willingness to pay higher gasoline prices to protect the environment.

To explore the source of the age-related differences in willingness to pay, we examine the roles of information and perceived risks in Section 3. Do people in different age groups have the same extent of knowledge of environmental issues? Do the perceived risks of global warming vary substantially by age? The evidence presented in this paper shows that while there are systematic age differences, they are not as stark as the willingness-to-pay disparities. 
The respective role of the different determinants of willingness-to-pay values is examined using regression analysis to control for demographic characteristics as well as information sources and perceived risks. As shown in Section 4, environmental risk information and risk beliefs each affect willingness-to-pay amounts in the expected manner. However, as is observed in the concluding Section 5, even after controlling for these and other influences there is an intergenerational gap, with older respondents less willing than younger respondents to pay more for gasoline that would be less harmful to the environment.

\section{Willingness-to-Pay Measures}

Before describing the key variables of interest, we begin with an overview of the data set. We use the Eurobarometer 51.1: Environmental Issues and Consumer Associations, April-May 1999 survey. ${ }^{5}$ Since 1970, the administrators of the Eurobarometer survey have undertaken a survey twice a year in each of 15 European Union countries. ${ }^{6}$ There are about 1,000 respondents in each of the 15 represented countries. The total sample size of Eurobarometer 51.1 is 16,144. After eliminating observations that were missing data on key variables, we use a sample size of 14,503 individual observations for our analysis.

The Eurobarometer survey includes information on demographic characteristics. Our interest here is in age differences, which are reported in this survey in bands of 10 years, ages 15-24, 25-34, 35-44, 45-54, 55-64, and age 65 and older. The regressions of

\footnotetext{
${ }^{5}$ Melich, Anna. Eurobarometer 51.1: Environmental Issues and Consumer Associations, April-May 1999 [computer file]. Brussels, Belgium: INRA (Europe) [Producer], 1999. 2nd ICPSR version. Ann Arbor, MI: Inter-University Consortium for Political and Social Research, 2001.

${ }^{6}$ Our analysis includes 17 countries, in that we treat Ireland and Northern Ireland as separate entities, as well as treat East Germany and West Germany as separate countries. The other countries included in the analysis are Austria, Belgium, Denmark, Finland, France, Germany, Greece, Italy, Luxembourg, The Netherlands, Portugal, Spain, Sweden, and the United Kingdom. Norway did not participate in the survey considered here, though Norway does participate in some Eurobarometer surveys.
} 
Section 4 also control for sex, marital status, education, and income, as well as variables for perceptions of urban problems such as traffic congestion and whether the respondent checked emissions in their car. More important, it also includes detailed perception and preference information pertaining to the risks of climate change and awareness of environmental issues.

Developing survey questions that elicit meaningful values of environmental policies poses considerable research challenges. As Fischhoff and Furby (1988) and Carson, Flores, and Meade (2001) have emphasized, such contingent valuation or stated preference studies should include well-defined commodities, a credible payment mechanism, and internal rationality tests to demonstrate the consistency of the answers. We will assess the performance of the Eurobarometer questions on these dimensions; however, even perfect performance on such criteria would not satisfy some critics. Risk analysts such as Adams (1995) express reservations about any survey effort to monetize environmental benefits. It may well be that the Eurobarometer survey responses and similar surveys lead to overstatements of people's actual willingness to pay. Our main concern, however, is not with absolute financial levels of support but with the variations of these amounts with key variables such as age and perceived risks of global warming.

Our policy valuation variable is willingness to pay a higher price for gasoline, referred to in the survey as "petrol." The willingness-to-pay questions are in two parts. First, the survey ascertained whether the respondent would be willing to pay more for petrol if doing so would protect the environment. In particular, for a series of products including petrol the survey asked: "For which, if any, of the following products and services would you be prepared to pay a little more now so that they are less harmful to 
the environment?" If the respondent indicated a willingness to pay more for petrol, the survey ascertained how much more: "Would you be prepared to pay 10 percent more, 20 percent more, or 30 percent more for it?",

Using these questions, as well as other information, we construct two different variables as measures of the respondents' willingness to pay for gasoline. First, we formulate an indicator variable for whether or not the subject is willing to pay more for petrol if doing so would protect the environment. Second, we analyze the percentage price increase that the respondent is willing to pay.

The survey's focus on gasoline prices has a number of attractive properties from the standpoint of being a meaningful willingness-to-pay question. First, paying more for gasoline is a credible payment mechanism that is more concrete than would be responses with respect to hypothetical interview money. The danger from purely hypothetical questions is that the willingness-to-pay responses may reflect general support for the environment as opposed to specific support for this policy initiative. Such influences are known as embedding effects. ${ }^{8}$ Gasoline is a well-defined commodity for which there is substantial awareness of prices and the opportunity costs involved of paying more for gasoline.

By comparison, previous survey questions pertaining to willingness to pay have been defined less precisely. For example, the World Values Survey that was the subject of research by Israel and Levinson (2004), as well as other researchers, asked respondents

\footnotetext{
${ }^{7}$ There were some additional issues regarding the construction of variables. Willingness to pay percentage amounts were coded based on the midpoints of the ranges. The survey also had an additional possible response of being willing to pay more than 30 percent for petrol, though only 0.4 percent of respondents fell into this group. For concreteness we will assign a 40 percent value to these people, but in the regression analysis using a 2-limit Tobit approach, we will estimate the percentage willingness to pay amounts without imposing any specific upper bound. The fuel price data came from GTZ Fuel Price Surveys $(1998,2000)$, available at http://www.internationalfuelprices.com.

${ }^{8}$ For description of these influences, see Kahneman and Knetsch (1992).
} 
the extent of their agreement with the statement, "I would buy things at 20 percent higher than usual prices if it would protect the environment." Unfortunately, this question does not specify which prices would be increased, so that the payment mechanism is not as concrete as it would be for an increase in gasoline prices. ${ }^{9}$

Table 1 summarizes the age variations in the responses to the different willingness-to-pay measures. In every case, the relatively low willingness-to-pay values suggest that respondents took these questions as a meaningful expression of willingness to pay, as opposed to a more general sign of support for the environment with no financial consequences. Perhaps in part due to the existence of already high gasoline prices in the European Union, only a minority of the respondents indicated a willingness to pay more for gasoline.

These willingness-to-pay amounts differ substantially. Notably, there is a steady decline in willingness-to-pay amounts with age. The bottom row of the table reports mean values for the pooled age 15-64 results. In every case, the mean values for those age 15-64 are higher and significantly different from those age 65 and over. In the case of the percentage of respondents who are willing to pay more for gasoline to protect the environment, those aged 15-24 are twice as likely to express such willingness as those 65 and over. In terms of the percentage amount more that the respondents are willing to pay, those aged 15-24 are willing to pay 2.8 percent more, as compared to 1 percent more for those 65 and over. Note that for these calculations, all those who did not express a willingness to pay more for gasoline received a zero value for the percent more that they were willing to pay.

\footnotetext{
${ }^{9}$ Other examples of willingness to pay questions can be found in Israel (2004) and Dunlap, Gallup, and Gallup (1993). Berk and Fovell (1999) explore willingness to pay measures for climate change policies using a sample of Los Angeles residents.
} 
The final two columns in Table 1 summarize the total cents more per liter that the respondent is willing to pay for gasoline. The third column in Table 1 provides the cents per liter that the respondent is willing to pay, conditional on being willing to pay a nonzero amount. These values exhibit only modest age variations, ranging from 9.1 cents per liter for those age 65 and over to a peak value of 12.5 cents per liter for those age 25 34. The observed differences are starker for the final column of results that reflect sample wide averages in willingness to pay including those responding they would pay zero amounts. Whereas those 65 and over are willing to pay an average of 1 cent per liter, the age 15-64 average is 2.3 cents and the value for those age $25-34$ is 2.7 cents.

\section{Information and Risk Beliefs}

Particularly among those age 65 and above there is a pronounced age-related decline in willingness to pay a higher gasoline tax to protect the environment. If these age-related differences can be traced to age-related factors such as shorter life expectancy, the prospects for changing their degree of political support are not bright. However, if the shortfall can be traced to a lack of information about the risks of global warming, then informational policies potentially could muster broader support for climate change initiatives. Previous studies have used large scale interviews as a technique that they call a "mental models" approach in which a small sample is interviewed in depth regarding their conceptualization of climate change issues. ${ }^{10}$ These studies have shown that the U.S. public often does not fully understand climate change. For example, they often confuse ozone depletion with global warming. The Eurobarometer survey does not

\footnotetext{
${ }^{10}$ See Kempton (1991a, 1997) for a mental models analysis, as well as Bostrom, Morgan, Fischhoff, and Read (1994). Read, Bostrom, Morgan, and Fischhoff (1994) report on a larger-scale interview study in the same vein.
} 
include questions that can be used to test the accuracy of beliefs, but it does include selfassessed degrees of knowledge and beliefs.

The Eurobarometer survey includes a series of questions that can be used to establish measures of the respondent's informational bases and perceived threat from climate change. One set of questions pertains to the individual's self assessment of whether he or she is informed about environmental risks. The particular question used in this analysis asked respondents how well they were informed about "major environmental problems, like holes in the ozone layer, global warming, the disappearance of forests, etc." For purposes of our subsequent regression analysis, we define three indicator variables equal to one for those who respond that they were very well informed, fairly well informed, or fairly badly informed about these major global environmental problems, and zero otherwise. The indicator variable group omitted from the regressions is people who were not informed at all, so that subsequent regression effects are relative to this uninformed group.

To provide an overview of these perceptions, in Table 2 we pool some of these groups to make the presentation of the results more parsimonious. Thus, in the first column we contrast those who are very well informed or fairly well informed with those who are badly informed or not informed at all. As the age group mean values reported in Table 2 indicate, roughly half of each age group considers themselves to be very well informed or fairly well informed about global environmental risks. The age group 65 and above has 47 percent who consider themselves to be well informed, as compared to 54 percent for the pooled age groups 15-64. Within this younger age band, the degree to 
which people are well informed does not vary greatly by age, as it ranges from 52 percent for those 55-64 to 56 percent for those 15-24.

Being aware of environmental problems does not necessarily mean that people believe that problems pose a risk to them. The first measure of risk belief is the extent to which respondents believe that climate change would affect their health. This measure reflects a combination of perceived climate change problems and their personal vulnerability to these problems. Once again, our regression analysis will use a detailed version of the variable, distinguishing with separate indicator variables those who believe climate change will affect health a lot, a little, or not at all. For the purposes of Table 2, we contrast those who believe it would affect health a lot with the pooled group of those who believe it would affect health a little or not at all. As the data in the second to last column in Table 2 indicate, roughly two-fifths of all age groups perceive a risk to their health. Those age 65 and over are significantly less likely to perceive a health risk, but the 3 percentage point difference with those age 15-64, although statistically significant, is not substantial.

The final risk perception question analyzed is the extent to which individuals are worried about the risks of global warming. The particular wording of the survey question asked respondents whether they were "very worried, somewhat worried, not very worried, or not at all worried" about a series of nine possible problems. Respondents who indicate that they were very worried about "global warming (greenhouse effect)" received a value of 1 for the variable that we call "very worried about global warming." Similarly, there are separate indicator variables for whether the respondent was "somewhat worried" or "not very worried", with "not at all worried" about global 
warming the omitted category in the regressions. In Table 2, we contrast the very worried group with the other three categories.

Those age 65 and over express lower degrees of worry about global warming than do the other age groups. As the values in the final column of Table 2 indicate, 33 percent of those age 65 and over are very worried about global warming, which is just over 4 percentage points less than those age 15-64. This measure of risk beliefs rises then falls with age, reaching a peak of 40 percent among those age $35-44$. Once again, these differences as well as the other pattern in Table 2 are not as pronounced as are the willingness-to-pay differences.

Could these differences in beliefs stem in part from a different informational base? People in different age groups rely on different information sources. Respondents were asked, "When you are looking for information on the environment, which of the following sources do you use?" followed by a list of nine sources such as newspapers and magazines, television, and friends. Use of newspapers or studies by environmental groups, for example, could affect not only the extent of one's knowledge but also the willingness to spend funds to address environmental risks. Table 3 reports usage of sources for environmental information for two age groups, those age 65 and above and those age 15-64. Three-fourths of the population use television as an information source, with somewhat greater usage by those age 65 and above. However, for every other category for which there are statistically significant differences, those age 15-64 are more likely to use that information source. The differences are particularly great for use of the internet, books, and information from environmental organizations. ${ }^{11}$ Overall, those age

\footnotetext{
${ }^{11}$ Some of these effects could, of course, be endogenous. Those with greater interest in environmental problems could seek out more information.
} 
65 and above draw on 2.3 information sources as compared to 2.7 for those under 65 .

Thus, both the number of sources used and the composition of the sources relied upon differ by age.

\section{Willingness-to-Pay Regression Estimates}

To distinguish the influences on willingness to pay of age versus factors correlated with age, it is instructive to consider regression estimates for the two willingness-to-pay questions in the Eurobarometer survey. To estimate the dichotomous choice of whether respondents are willing to pay more for gasoline to protect the environment, we use probit regression and report estimates for which the coefficients have been transformed to reflect marginal probabilities. The additional percentage amount that respondents are willing to pay for gasoline poses two econometric issues, the many responses at the lower bound of zero and the unbounded category of possible responses, which was "over 30 percent." The double bounded Tobit estimates for the gasoline price percentage increase addresses each of these concerns. We report Tobit coefficients that are the unconditional marginal effects of each variable.

For both of these willingness-to-pay measures, Table 4 reports estimates by age group with and without the set of risk perception variables and the indicator variables for different information sources. Each equation also includes an extensive set of additional characteristic variables and country indicator variables. Specifically, all equations control for income, education, indicator variables for gender and marital status, and country of residence. The equations controlling for risk perceptions and information sources reported in columns 2 and 4 also control for whether the respondent checks automobile emissions. The check emissions variable, which has a significant positive 
effect, provides a validity test for whether private actions are consistent with the expressed willingness-to-pay measure. The omitted age group is age 65 and over so that all age coefficients are interpreted relative to this group.

The results in columns 1 and 2 in Table 4 for whether the respondent is willing to pay more indicate that the age 65 and over group has a significantly lower willingness to pay any positive amount relative to all other groups. For this discrete response, people in older age brackets have a 0.05 to 0.09 lower probability of being willing to pay more for gasoline even after including extensive controls for other demographic influences. The results for the percent higher gas price one is willing to pay, reported in columns 3 and 4 of Table 4, follow a similar pattern of a drop-off with age in willingness to pay. Although not all of the age category coefficients are significantly different from one another, there is a steadily declining pattern by age for both sets of results and a significant difference with those aged 65 and over.

The steepest decline in both the probit and Tobit estimates is for those age 65 and above relative to the age 55-64 group. The drop-off in the estimated effect by moving into that age group is of roughly the same magnitude as the observed drop between the age groups 15-24 and 55-64. Thus, the effects of the age variable are not proportional to remaining life expectancy.

Each equation also includes a set of personal characteristic variables. Neither gender nor marital status are influential, but education levels and, to a lesser extent, income, boost the level of support for higher petrol prices to protect the environment. Education and income will reflect the respondent's affluence in terms of lifetime wealth and current income levels. If environmental amenities are a normal economic good, the 
person's willingness to pay for environmental policies should increase with income. However, the support being examined in this survey is in terms of higher petrol prices, not a lump sum donation to protect the environment. If the amount of gas purchased increases substantially with income, the effect of income on support for a gas tax is ambiguous even if overall willingness to pay to protect the environment increases with income. $^{12}$ The estimates in Table 4 control for gasoline consumption to the extent that is feasible with the Eurobarometer data in that car usage will be reflected in the check emissions variables and the country variables. The possibly competing effects of higher petrol prices as a policy instrument may account for the weaker effect of income levels on support for higher gas prices, as compared to the influence of education levels, which proxy lifetime wealth.

The equations in columns 2 and 4 in Table 4 add measures of risk belief, risk knowledge, and risk information. The effects on whether the respondent is willing to pay, which are shown in column 2, are very similar to the percentage amount results in column 4, so we will discuss them together. Each of the willingness-to-pay measures increases if the person is very worried or somewhat worried about global warming, and there is no significant effect of being not very worried about global warming. In terms of the magnitude of the effects, being very worried increases the probability of supporting higher gas prices by 0.08 , and being somewhat worried boosts this probability by 0.05 . These effects are relative to the omitted indicator variable category of not being worried at all. The declining pattern of coefficients as the degree of worry decreases also follows the expected pattern.

\footnotetext{
${ }^{12}$ Hersch and Viscusi (2004) develop an economic model that illustrates these effects.
} 
Whether people believe that climate change will affect their own health also influences whether they support higher petrol prices and the amount of such a price increase in the expected direction. If climate change is believed to affect one's health a lot, the probability of support is 0.04 higher, and it is 0.02 higher if climate change will affect health a little.

These two sets of results for worry about climate change and perceived effects of climate change on health share a consistent theme. On a theoretical basis, the degree of support for an increase in petrol price should increase with the extent of the risk that is being addressed. ${ }^{13}$ This overall relationship is clearly borne out in these results, both in terms of the direction of effects and the declining magnitude of the effects for less strongly held risk beliefs.

The degree to which the respondent is informed at all about environmental problems has effects of comparable magnitude. Relative to not being informed at all about environmental problems, being fairly well informed raised the probability of support by 0.05 , and being either very well informed or fairly badly informed raises the probability of support by 0.03 .

Many specific individual information sources also have incremental effects on willingness to pay even after accounting for these risk belief variables. In terms of magnitude, the strongest influences are the positive coefficients for books, information provided by environmental organizations, and the internet. These are all sources that those age 65 and above use at a lower rate than do younger age groups. Information sources used extensively by the oldest age group - television and radio - have comparatively minor effects.

\footnotetext{
${ }^{13}$ Hersch and Viscusi (2004) for a derivation of this result, which is unambiguous.
} 
The differences by country are interesting as well. The omitted country category is Austria. Consider the results in column 1 of Table 4 for whether the respondent favors higher gas prices to protect the environment. Residents in two countries, East Germany and France, have a significantly lower probability of supporting higher prices; however, respondents in 10 other countries have significantly higher probabilities of such support. Countries with strong environmental movements and substantial vulnerability to the flooding risks of global warming display especially strong levels of support. The countries for which respondents have a probability of support of at least 0.10 greater than Austria are Denmark, Greece, Italy, Luxembourg, and Sweden.

Even after controlling for this diverse set of risk perceptions and informational factors, the pronounced age variations remain and are reduced in magnitude by only a modest amount. Differences in demographic background, risk beliefs, extent of knowledge, information sources, and country of residence do not account for the substantial intergenerational gap in willingness to pay.

\section{Conclusions}

Given the long time lag before any climate change initiatives can produce demonstrable policy results, there has long been speculation in the literature that support for climate change policies may differ substantially across the population based on individual age. To examine whether there are important intergenerational differences in support for global warming policies, this article examined a large sample of respondents to the 1999 Eurobarometer survey. The detailed data available in the survey makes it possible to analyze both the overall levels of environmental risk information and 
willingness to pay for environmental initiatives while controlling for background factors that may influence these outcomes.

The respondents' willingness to pay higher gasoline prices to address environmental problems revealed stark age-related differences. For each of the measures of willingness to pay considered, there was an overall drop-off in the willingness-to-pay value with age. Those over age 65 were half as likely to be willing to pay more for gasoline and, on average, were willing to pay just over one-third as much as were people aged 15-24.

A possible explanation for the willingness-to-pay differences is that there are agerelated differences in environmental risk information and concern about environmental risks. Sources of environmental risk information also differ by age. Younger age groups are more likely to avail themselves of almost every form of available information sources, ranging from drawing upon newspaper articles to reading reports from environmental groups. While there are in fact unambiguous age-related differences in environmental risk information and risk beliefs, these influences do not account for a great deal of the age-related variation in willingness to pay.

What these results suggest is that the concrete support that people may exhibit for climate change policies cannot be traced solely to a disinterested bequest motive with respect to future generations. Younger age groups may believe that they will personally benefit more from climate change policies. In addition, their children will also benefit to a larger extent, since they are even younger, so that concerns with respect to the next generation will reap a longer-term benefit for younger respondents than for older respondents. For countries such as the United States, for which there is going to be a 
substantial growth in the percentage share of the age 65 and over population, there may be a decline in the overall country's political support for climate change policies unless they can be characterized in a manner that better addresses the concerns of the older segments of the population. 


\section{Works Cited}

Adams, J.: 1995, Risk, University College London Press, London.

Aldy, J.E., Barrett, S., and Stavins, R.N.: 2003, 'Thirteen Plus One: A Comparison of Global Climate Policy Architectures', Climate Policy 3, 373-397.

Barrett, S.: 2003, Environment and State Craft, Oxford University Press, Oxford.

Berk, R.A., and Fovell, R.G.: 1999, 'Public Perceptions of Climate Change: A "Willingness to Pay" Assessment', Climatic Change 41 (3-4), 413-446.

Bostrom, A., Morgan, M.G., Fischhoff, B., and Read, D.: 1994, 'What Do People Know about Global Climate Change?: 1. Mental Models', Risk Analysis 14 (6), 959-970.

Carson, R., Flores, N., and Meade, N.: 2001, 'Contingent Valuation: Controversies and Evidence', Environmental and Resource Economics 19, 173-210.

Dunlap, R.E., Gallup, G.H., and Gallup, A.M.: 1993, 'Results of the Health of the Planet Survey', Environment 35 (9), 33-39.

Fischhoff, B., and Furby, L.: 1988, 'Measuring Values: A Conceptual Framework for Interpreting Transactions with Special Reference to Contingent Valuation of Visibility', Journal of Risk and Uncertainty 1, 147-184.

Hersch, J., and Viscusi, W.K.: 2004, 'Paying for Climate Change Policies in Europe', Harvard Law School Olin discussion paper 503.

Israel, D.K.: 2004, 'International Support for Environmental Protection', Environment and Development Economics, 9 (6), 781-802.

Israel, D.K., and Levinson, A.: 2004, 'Willingness to Pay for Environmental Quality: Testable Empirical Implications of the Growth and Environment Literature', Contributions to Economic Analysis \& Policy 31 (1), article 2.

Kahneman, D., and Knetsch, J.: 1992, 'Valuing Public Goods: The Purchase of Moral Satisfaction', Journal of Environmental Economics and Management 22 (1), 57 70 .

Kempton, W.: 1991a, 'Public Understanding of Global Warming', Society and Natural Resources 4 (4), 331-345.

Kempton, W.: 1991b, 'Lay Perspectives on Global Climate Change', Global Environmental Change 1 (3), 183-208. 
Kempton, W.: 1997, 'How the Public Views Climate Change', Environment 39 (9), 1221.

Kempton, W., and Craig, P.: 1993, 'European Thinking on Global Climate Change', Environment 35 (3), 16-20.

Löfstedt, R.: 1991, 'Climate Change Perceptions and Energy-use Decisions in Northern Sweden', Environmental Change 1, 321-324.

Read, D., Bostrom, A., Morgan, M.G., and Fischhoff, B.: 1994, 'What Do People Know about Global Climate Change?: 2. Survey Studies of Educated Lay People', Risk Analysis 14 (6), 971-982.

Read, D., and Read, N.L.: 2004, 'Time Discounting over the Lifespan', Organizational Behavior and Human Decision Processes 94, 22-32.

Schelling, T.C.: 1997, 'The Cost of Combating Global Warming: Facing the Tradeoffs', Foreign Affairs 76 (6), 8-14.

Stewart, R.B., and Wiener, J.B.: 2003, Reconstructing Climate Policy: Beyond Kyoto, The AEI Press, Washington, DC.

von Amsberg, J.: 1995, 'Excessive Environmental Risks: An Intergenerational Market Failure', European Economic Review 39 (8), 1447-1464. 


\section{Table 1}

\section{Willingness to Pay for Petrol That Is Less Harmful}

to the Environment, by Age Group

\begin{tabular}{ccccc} 
Age Group & $\begin{array}{c}\text { Percentage Who } \\
\text { are Willing to } \\
\text { Pay More }\end{array}$ & $\begin{array}{c}\text { Percent } \\
\text { Amount More } \\
\text { Willing to Pay }\end{array}$ & $\begin{array}{c}\text { Cents More per } \\
\text { Liter Willing to } \\
\text { Pay if Positive }\end{array}$ & $\begin{array}{c}\text { Cents More per } \\
\text { Liter Willing to } \\
\text { Pay }\end{array}$ \\
\hline $15-24$ & 22.1 & 2.8 & 11.8 & 2.6 \\
$25-34$ & 21.2 & 2.8 & 12.5 & 2.7 \\
$35-44$ & 19.4 & 2.3 & 11.7 & 2.3 \\
$45-54$ & 18.3 & 2.1 & 10.7 & 2.0 \\
$55-64$ & 16.4 & 1.6 & 9.5 & 1.6 \\
$65+$ & 10.9 & 1.0 & 9.1 & 1.0 \\
All age $15-64$ & $19.7 *$ & $2.4 *$ & $11.5 *$ & $2.3 *$ \\
\hline
\end{tabular}

* Asterisks indicate statistically significant differences between the age 15-64 and age $65+$ age groups, $5 \%$ level, two-tailed test. 
Table 2

\section{Climate Change and Environmental Risk Beliefs, by Age Group}

\begin{tabular}{cccc} 
Age Group & $\begin{array}{c}\text { Very Well Informed or } \\
\text { Fairly Well Informed } \\
\text { about Major Global } \\
\text { Environmental Problems }\end{array}$ & $\begin{array}{c}\text { Climate Change } \\
\text { will Affect Health } \\
\text { a Lot }\end{array}$ & $\begin{array}{c}\text { Very Worried about } \\
\text { Global Warming }\end{array}$ \\
\hline $15-24$ & 56.0 & 38.3 & 36.3 \\
$25-34$ & 54.6 & 40.5 & 37.8 \\
$35-44$ & 54.4 & 40.0 & 40.0 \\
$45-54$ & 54.4 & 38.2 & 37.4 \\
$55-64$ & 52.3 & 39.3 & 35.9 \\
$65+$ & 47.4 & 35.8 & 33.4 \\
All age $15-64$ & $54.4^{*}$ & $39.3 *$ & $37.6^{*}$ \\
\hline
\end{tabular}

* Asterisks indicate statistically significant differences between the age 15-64 and age $65+$ age groups, $5 \%$ level, two-tailed test. 
Table 3

Environmental Information Sources by Age

Under 65

65 and older

Percent using source:

Newspapers \& Magazines

65.1

$59.0 *$

Radio

38.9

40.8

Television

75.0

$77.5^{*}$

Government Publications

10.7

$9.2^{*}$

Environmental Organizations

16.3

$9.0 *$

Books

17.6

$8.1 *$

Internet

10.0

$1.2 *$

Research Centers

6.0

$3.0 *$

Friends

30.5

$23.3^{*}$

Total number of sources

2.7

$2.3^{*}$

* Asterisks indicate statistically significant differences between the age 15-64 and age $65+$ age groups, $5 \%$ level, two-tailed test. 


\section{Table 4}

\section{Regression Estimates of Willingness to Pay for Petrol}

\section{Less Harmful to the Environment ${ }^{\mathrm{a}}$}

(1)

Willingness

to pay more

$(0-1)$

Age 15-24

Age 25-34

Age 35-44

Age 45-54

Age 55-64

Male

Married

Education

Education - still studying

Income x 10,000

Income missing

Very worried about global warming

$0.086^{* *}$

(0.014)

$0.060 * *$

(0.014)

$0.054 * *$
$(0.015)$

\section{$-0.006$}

(0.007)

(0.001)

(0.014)

$$
\text { (0.003) }
$$

(0.009)
(2)

(3)

(4)

Willingness Percent more Percent more to pay more willing to willing to pay $(0-1)$ pay

$\begin{array}{llcc}0.094 * * & 0.078 * * & 1.281 * * & 1.024 * * \\ (0.017) & (0.017) & (0.175) & (0.169)\end{array}$

$0.073 * *$

$1.262 * *$

$1.050 * *$

(0.014)

$(0.147)$

$(0.142)$

$\begin{array}{cccc}0.073 * * & 0.055^{* *} & 1.025 * * & 0.773 * * \\ (0.014) & (0.014) & (0.150) & (0.144)\end{array}$

$0.046^{* *}$

$0.804 * *$

$0.608 * *$

(0.014)

$(0.155)$

(0.149)

$0.045 * *$

$0.666^{* *}$

$0.530 * *$

(0.014)

(0.160)

(0.153)

$-0.003$

$-0.047$

(0.077)

0.013

(0.006)

0.068

(0.090)

0.027

0.006

(0.007)

$0.087 * *$

(0.010)

$0.048 * *$

(0.010)

(0.001)

$0.419 * *$

(0.152)

0.252

0.016

(0.013)

(0.147)

0.001

(0.003)

$0.074 *$

(0.033)

0.031

(0.032)

$-0.019 *$

$-0.201$

$-0.208$

(0.009)

(0.117)

(0.113)

$0.078 * *$

$0.889 * *$ (0.021)

(0.231) 
(1)

Willingness Willingness Percent more Percent more to pay more to pay more willing to willing to pay

$(0-1)$ $(0-1)$ pay

Somewhat worried about global warming

Not very worried about global warming

Climate change will affect health a lot

Climate change will affect health a little

Very well informed about environmental problems

Fairly well informed about environmental problems

Fairly badly informed about environmental problems

Check emissions

Check emissions missing

Newspapers and magazines

Radio

Television

Government publications

Environmental

organizations
$0.053 * *$

(0.020)

0.031

(0.021)

$0.038^{* *}$

(0.011)

$0.023 *$

(0.010)

0.030

(0.017)

$0.047 * *$

(0.012)

$0.026 *$

(0.012)

$0.022 * *$

(0.007)

0.008

(0.010)

$0.027 * *$

(0.007)

$-0.005$

(0.007)

0.020 *

(0.008)

$0.023 *$

(0.011)

$0.043 * *$

(0.010)
$0.614 * *$

(0.228)

0.286

(0.237)

$0.479 * *$

(0.121)

$0.264 * *$

(0.112)

0.254

(0.184)

$0.491 * *$

(0.137)

0.249

(0.137)

$0.220 * *$

(0.085)

0.182

(0.114)

$0.372 * *$

(0.089)

$-0.064$

(0.082)

0.171

(0.096)

$0.320 * *$

(0.120)

$0.534 * *$

(0.124) 
(1) (2) (3) (4)

Willingness Willingness Percent more Percent more to pay more to pay more willing to willing to pay

Books

$(0-1)$ $(0-1)$ pay

Internet

Research

Friends

Belgium

Denmark

East Germany

Finland

France

Great Britain

Greece

Ireland

Italy

Luxembourg

$0.051 * *$

(0.010)

$0.042 * *$

(0.012)

0.004

(0.013)

$0.028 * *$

(0.007)
$0.643 * *$

(0.099)

$0.534 * *$

(0.124)

0.091

(0.153)

$0.376 * *$ (0.081)

$\begin{array}{lccc}-0.019 & 0.012 & -0.293 & 0.087 \\ (0.018) & (0.021) & (0.241) & (0.235)\end{array}$

$\begin{array}{cccc}0.132 * * & 0.165^{* *} & 2.017 * * & 2.475 * * \\ (0.026) & (0.028) & (0.238) & (0.232)\end{array}$

$-0.054 * * \quad-0.057 * * \quad-0.675^{* *}$

$-0.677 * *$

(0.017)

(0.016)

$(0.258)$

(0.250)

$\begin{array}{cccc}0.036 & 0.042 & 0.467 * & 0.540 * \\ (0.021) & (0.022) & (0.229) & (0.225)\end{array}$

$-0.035^{*}$

0.000

$-0.456$

$-0.020$

(0.018)

(0.020)

(0.244)

(0.237)

$\begin{array}{cccc}0.061 * * & 0.076 * * & 0.733 * * & 0.904 * * \\ (0.022) & (0.023) & (0.228) & (0.223)\end{array}$

$0.241 * *$

$0.256 * *$

$3.542 * *$

$3.707 * *$

(0.027)

(0.028)

(0.218)

$(0.213)$

$\begin{array}{llll}0.061 * * & 0.110^{* *} & 0.520^{*} & 1.091 * * \\ (0.023) & (0.026) & (0.235) & (0.233)\end{array}$

$0.119 * *$

$0.138 * *$

$1.438 * *$

$1.704 * *$

(0.024)

(0.025)

(0.224)

(0.220)

$\begin{array}{llcc}0.103 * * & 0.100 * * & 1.211 * * & 1.173 * * \\ (0.027) & (0.027) & (0.255) & (0.245)\end{array}$


(1) (2) (3) (4)

Willingness Willingness Percent more Percent more to pay more to pay more willing to willing to pay

Netherlands

$(0-1)$ $(0-1)$ pay

$0.082 * *$

$0.079 * *$

$1.218 * *$

$1.147 * *$

$(0.023)$

(0.023)

(0.223)

(0.219)

Northern Ireland

0.027

$0.070 *$

0.159

0.672 *

(0.030)

(0.034)

(0.342)

(0.332)

Portugal

$0.056 *$
$(0.023)$

$0.083 * *$

$0.499 *$

$0.847 * *$

(0.023)

(0.025)

(0.242)

(0.237)

Spain

$0.053 *$

$0.088 * *$

$0.731^{* *}$

$1.183 * *$

(0.022)

(0.025)

(0.234)

(0.230)

Sweden

$\begin{array}{llcc}0.158 * * & 0.176 * * & 2.076 * * & 2.275 * * \\ (0.025) & (0.026) & (0.223) & (0.217)\end{array}$

West Germany

$\begin{array}{cccc}0.007 & 0.002 & 0.052 & 0.011 \\ (0.020) & (0.020) & (0.241) & (0.233)\end{array}$

Standard errors in parentheses. The sample size for each regression is 14,503.

$*$ significant at $5 \%$; ** significant at $1 \%$.

a. Columns 1 and 2 estimated by probit, columns 3 and 4 estimated by Tobit. Probit coefficients report marginal effects, Tobit coefficients report unconditional marginal effects. 